\title{
Patient satisfaction with primary healthcare services: are there any links with patients' symptoms of anxiety and depression?
}

\author{
Rima Kavalniene $\dot{1}^{*}$ D, Aušra Deksnyte ${ }^{2,3}$, Vytautas Kasiulevičius ${ }^{1}$, Virginijus Šapoka', Ramūnas Aranauskas 2,3 \\ and Lukas Aranauskas ${ }^{4}$
}

\begin{abstract}
Background: The aim of our study was to determine the association of anxiety and depression symptoms, as well as the main socio-demographic factors, with patients' satisfaction with primary healthcare services.

Methods: The respondents were asked to fill out an anonymous questionnaire that included information on the patients' gender, age, place of residence, education, ethnicity, the type of clinic they visited and the presence of chronic diseases. Patient satisfaction was evaluated by using a short version of the Patient Satisfaction Questionnaire. We also used the Hospital Anxiety and Depression Scale.

Results: Poor evaluations of primary healthcare services were more characteristic of males, older patients, those living in district centres and villages, individuals with lower (secondary or lower) education levels, respondents of Russian ethnicity (compared to Lithuanian), patients with chronic diseases and higher anxiety and depression symptom scores. In the final regression analysis, better satisfaction with primary healthcare services was observed in respondents who were less depressed, of Polish ethnicity and who were living in a city rather than a village.

Conclusions: Being more depressed or anxious, living in the district centre or countryside related to patients' worse satisfaction with primary healthcare services. The results of nationality of patients and their satisfaction are ambiguous. The is strong correlation between the symptoms of depression and anxiety.
\end{abstract}

Keywords: Patient satisfaction, Primary healthcare, Depression symptoms, Anxiety symptoms

\section{Background}

Social and demographic factors as well as the presence of illnesses affect the formation of patients' attitudes, their satisfaction with healthcare services and their expectations related to these services. The associations between satisfaction with healthcare services and a broad spectrum of factors have been researched, yet studies on the links between patients' mental disorders and their satisfaction with primary healthcare (PHC) services are relatively scarce. As many as $24 \%$ of patients who visit PHC physicians have mental disorders [1], and anxiety disorders and depression are among the most common

\footnotetext{
*Correspondence: rimabelunska@gmail.com

${ }^{1}$ Institute of Clinical Medicine of the Faculty of medicine of Vilnius University, Clinic of Internal Diseases, Family Medicine and Oncology, Santariskiu g. 2, Vilnius, Lithuania

Full list of author information is available at the end of the article
}

of them $[2,3]$. Patients with anxiety are more irritable and impatient and have greater difficulty focusing their attention [4-6], depressed patients have more difficulty participating in and managing most areas of their lives, and such patients are frequently characterized by less constructive thinking $[1,6,7]$. All of this may negatively affect the evaluation of PHC services. The negative effect of depression on certain aspects of satisfaction with PHC services is also seen in patients with such conditions as breast tumours [8], cardiac diseases [7], type-2 diabetes mellitus [9], patients undergoing dialysis [10], etc. In patients undergoing surgery for cataracts [11], in patients who have sustained traumas [12] and those with breast tumours [13], higher degrees of anxiety were associated with greater levels of dissatisfaction with healthcare services. Given the fact that depressive and anxiety disorders are among the most common mental disorders

(c) The Author(s). 2018 Open Access This article is distributed under the terms of the Creative Commons Attribution 4.0 International License (http://creativecommons.org/licenses/by/4.0/), which permits unrestricted use, distribution, and reproduction in any medium, provided you give appropriate credit to the original author(s) and the source, provide a link to the Creative Commons license, and indicate if changes were made. The Creative Commons Public Domain Dedication waiver (http://creativecommons.org/publicdomain/zero/1.0/) applies to the data made available in this article, unless otherwise stated. 
that PHC physicians face in their work [2, 3], and that these disorders affect patients' everyday lives as they are linked to disability and poorer quality of life $[14,15]$, it is interesting and useful to know how these disorders along and their interaction with the main socio-demographic factors affect patients' satisfaction with primary level healthcare services. In our study, we decided to look for a link between satisfaction with the symptoms of anxiety and depression, but not with the diagnosis of these diseases, because we believe that it will more accurately and more sensitively show the relationship between the current emotional state of the patient and the assessment of PHC services. The authors hypothesize that the presence of anxiety and depressive symptoms negatively affects the assessment of PHC services and that the expectations of patients with these symptoms are not fully fulfilled.

The aim of our study was to determine the associations of patients' anxiety and depression symptoms, as well as the main socio-demographic factors, with patients' satisfaction with PHC services. This study will attempt to assess whether the expectations of depressed and anxious patients are being implemented. It is expected to reveal the most problematic points for the range of services provided to such patients, whose correction would allow for the optimization and improvement of the quality of services provided for them.

\section{Methods}

This study was carried out in Vilnius area in Lithuania, during 2016-2017. This region has a population of around 640,000 served by 63 PHC centres. As we wanted to get sufficient groups of patients with depression and anxiety symptoms (min 100 patients with each symptoms group), a sample size of 800 was appropriate. The survey of patients was carried out at 24 PHC institutions and the total number of questioned patients was 889. The questionnaire was given to patients who for various reasons visited their PHC centres and agreed to participate in the study. The main inclusion criteria were to be aged over 18 and have the ability to properly understand and fill out a questionnaire. The respondents were asked to fill out an anonymous questionnaire that included information on the patients' gender, age, place of residence, education, ethnicity, the type of clinic they visited (state-owned or private) and the presence of chronic diseases (except for depression and anxiety, if any). Patients were asked to point their chronic diseases from the offered to them list of the diseases. This list was formed with reference to list of 16 diseases of comorbidity components of Charlson Comorbidity Index. Patient was evaluated as having chronic diseases when at least one disease was marked. The type of the clinic (state-owned or private) depended only on whether the owner of the premises was a state-financed or private individual, because healthcare services at clinics of both types are financed by state funds.

Patient satisfaction was evaluated by using an adapted short version of the Patient Satisfaction Questionnaire (PSQ-18, Marshall and Hays). The questionnaire consists of 18 closed-type questions and is used for the evaluation of patients' satisfaction with medical services in six main domains: General Satisfaction, Technical Quality, Interpersonal Manner, Communication, Financial Aspects, Time Spent with the Doctor, and Accessibility and Convenience. We also evaluated the total sum score of all subscales. The subjects had five options when answering each question: Strongly Agree, Agree, Uncertain, Disagree and Strongly Disagree. Respondents received from 1 to 5 points for each answer, where 5 meant the highest satisfaction. According to the PSQ-18 scoring system, the sum score of all subscales may range from 18 to 90 points, where 18 points is the poorest possible evaluation and 90 points the best. To evaluate the internal consistency of the questionnaire, Cronbach's alpha coefficient (0.96) was calculated and was found to be very good.

We also used the Hospital Anxiety and Depression Scale (HAD, Zigmond and Snaith). The scale is translated into Lithuanian and has been widely used since 1991. The HAD scale consists of 7 questions aimed at evaluating symptoms of depression (the HAD-D subscale) and 7 questions for an evaluation of symptoms of anxiety (the HAD-A subscale). The sum score in each subscale may range from 0 to 21 points. The scores indicate the severity of the symptoms of depression or anxiety: from 0 to 7 points, normal anxiety or mood; from 8 to 10 points, mild symptoms of depression or anxiety; from 11 to 14 points, moderate; and from 15 to 21 points, severe symptoms of depression or anxiety. The internal reliability and consistency of each HAD subscale was evaluated by calculating Cronbach's alpha, which was 0.87 and was evaluated as good.

Statistical data analysis was conducted using the Statistical Package for Social Sciences (SPSS), version 24.0. A database was created for the processing of questionnaire data. To set coding and input errors, we used the procedure 'frequencies', where we set the minimum and maximum values for each of the answers and if they exceeded the ones contained in the questionnaire, we corrected them according to the source material. We also used 'frequencies' for the response frequency calculations.

For the statistical distribution of the frequency of responses between the discrete (nominal and ordinal) data the non-parametric Pearson's chi square $\left(\mathrm{x}^{2}\right)$ criterion is chosen with $95 \%$ probability, i.e., the difference is considered statistically reliable at $p<0.05$. For determining the strength and direction of statistical correlations 
between data the non-parametric Spearman correlation coefficient is chosen, when $\mathrm{p}<0.05$. Using the Spearman coefficient does not matter if the variable values are symmetric. In the results with means, the standard deviation from the mean (SD) was also indicated.

The One Way ANOVA test was used to compare the means of total PSQ-18 scores, PSQ-18 subscales' scores as well as HAD subscales' scores according to patients' socio-demographic factors; Post-Hoc tests were used to compare three or more groups. The effect of all demographic and social factors and anxiety and depression symptoms on patient satisfaction and its strength was assessed using an ordinal regression analysis. As a dependent ordinal variable, we used the evaluation of patients' satisfaction, which we obtained by splitting the overall PSQ-18 score into three ranks: good (PSQ-18 score from 90 to 66), medium (from 65 to 42) or poor (from 41 to 18 ) evaluation. In the education, nationality and place of residence groups, we used secondary and lower education, Lithuanian nationality and urban life as comparable variables, because we were expecting the biggest differences in satisfaction with these groups.

The study proposal was approved by the Regional Biomedical Research Ethics Committee in Vilnius, Lithuania.

\section{Results}

In total, 889 patients filled out the questionnaire. Two questionnaires were excluded from the analysis because of filling errors or incomplete filling, and thus 887 questionnaires were included in the data analysis. The respondents' distribution according to their socio-demographic and other characteristics is presented in Table 1.

\section{Associations according to patient satisfaction questionnaire (PSQ-18)}

The total PSQ-18 scores ranged from 21 to 90 points, the mean score being $59.9 \pm 14.6$ points. The majority, i.e. $44 \%$ of the patients, evaluated the PHC services as good (90 to 66 points), $38 \%$ of the respondents gave average evaluations (65 to 42 points) and the lowest percentage of respondents (18\%) evaluated PHC services poorly (41 to 0 points). Poor evaluations of PHC services were more characteristic of males, older patients, those living in district centres and villages, individuals with lower (secondary or lower) education levels, respondents of Russian ethnicity (compared to Lithuanian) and patients with chronic diseases $(\rho<0.05)$. Patients of state-owned clinics more frequently presented average evaluations, patients of private clinics good evaluations, while the frequency of poor evaluations did not differ between these two groups.

The most positive evaluations were observed in the Interpersonal Manner and Communication subscales (mean scores 3.59 and 3.55, respectively). The poorest evaluations were observed in the statements of the
Table 1 Respondents' distribution according to their sociodemographic and other characteristics

\begin{tabular}{|c|c|c|}
\hline Respondents' characteristics & Number of respondents & Percent \\
\hline \multicolumn{3}{|l|}{ Gender } \\
\hline Male & 356 & $40.1 \%$ \\
\hline Female & 531 & $59.9 \%$ \\
\hline \multicolumn{3}{|c|}{ Age group } \\
\hline $18-40$ years & 298 & $33.6 \%$ \\
\hline $41-60$ years & 388 & $43.7 \%$ \\
\hline $61-87$ years & 201 & $22.7 \%$ \\
\hline \multicolumn{3}{|c|}{ Living area } \\
\hline City & 715 & $80.6 \%$ \\
\hline District centre & 78 & $8.8 \%$ \\
\hline Village & 94 & $10.6 \%$ \\
\hline \multicolumn{3}{|c|}{ Education level } \\
\hline Secondary or lower & 280 & $31.6 \%$ \\
\hline Specialized secondary & 151 & $17.0 \%$ \\
\hline Higher & 429 & $48.4 \%$ \\
\hline Other & 27 & $3 \%$ \\
\hline \multicolumn{3}{|c|}{ Ethnicity } \\
\hline Lithuanian & 520 & $58.6 \%$ \\
\hline Russian & 173 & $19.5 \%$ \\
\hline Polish & 175 & $19.7 \%$ \\
\hline Other & 19 & $2.1 \%$ \\
\hline
\end{tabular}

Type of PHC clinic

\begin{tabular}{lcc} 
State-owned & 685 & $77.2 \%$ \\
Private & 202 & $22.8 \%$ \\
& & \\
& Chronic diseases & $57.6 \%$ \\
Yes & 511 & $42.4 \%$ \\
No & 376 & $100.0 \%$ \\
\hline Total & 887 & \\
\hline
\end{tabular}

Accessibility and Convenience and Time Spent with the Doctor subscales (mean scores 2.97 and 3.20, respectively).

\section{Associations according to depression and anxiety symptoms}

The evaluation of the scores of the HAD scale showed that $290(32.7 \%)$ patients had symptoms of anxiety of any level, and 193 (21.8\%) had symptoms of depression of any level. The frequency of the levels of the severity of symptoms of depression and anxiety among the 
subjects is presented in Table 2. The results obtained showed that $88 \%$ of all patients who had symptoms of depression of any level also had symptoms of anxiety, and $58.6 \%$ of all patients with anxiety had symptoms of depression as well. Both subscales of anxiety and depression strongly correlated with each other (Spearman's correlation coefficient $0.742 ; \rho<0.001$ ).

Higher scores in the depression subscale were associated with male gender, older age, living in a district centre or village, poorer education, the presence of chronic diseases and being of Russian or Polish rather than Lithuanian ethnicity $(\rho<0.015)$. Meanwhile, higher scores in the anxiety subscale were associated only with older age (Spearman's correlation coefficient $0.228 ; \rho<$ $0.001)$ and the presence of chronic diseases $(\rho<0.001)$.

Poorer scores in both HAD subscales correlated with a poorer total PSQ-18 score and poorer scores in all subscales $(\rho<0.001)$ (Table 3$)$.

\section{Regression analysis}

In the beginning, we carried out ordinal regression analysis only with the socio-demographic factors and patient satisfaction with PHC services (Nagelkerke $=0.100$ ) (Table 4). We saw a link between the assessment of better satisfaction with the younger age of respondents, special secondary education, Polish nationality and the place of residence in the city rather than in the district centre or village.

Since there was a strong inter-correlation between both HAD subscales (symptoms of anxiety and depression), we carried out separate regression analyses with each subscale and subsequently joined both HAD subscales and evaluated the joint result. We also added the presence of chronic diseases if any. In regression analysis with the HAD depression subscale and socio-demographic factors, a better total PSQ-18 score correlated with lower depression scores, Polish ethnicity and living in a city rather than a village (Nagelkerke $=0.385$ ) (Table 5). In regression analysis with the HAD anxiety subscale and socio-demographic factors, a better total PSQ-18

Table 2 Frequency of respondents' levels of severity of symptoms of depression and anxiety

\begin{tabular}{|c|c|c|c|c|}
\hline \multirow{2}{*}{$\begin{array}{l}\text { Level of severity } \\
\text { of symptoms }\end{array}$} & \multicolumn{2}{|l|}{ Anxiety scale } & \multicolumn{2}{|c|}{ Depression scale } \\
\hline & $\begin{array}{l}\text { Number of } \\
\text { respondents }\end{array}$ & $\%$ & $\begin{array}{l}\text { Number of } \\
\text { respondents }\end{array}$ & $\%$ \\
\hline Normal mood & 597 & $67.3 \%$ & 694 & $78.2 \%$ \\
\hline Mild symptoms & 146 & $16.5 \%$ & 106 & $12 \%$ \\
\hline Moderate symptoms & 127 & $14.3 \%$ & 63 & $7.1 \%$ \\
\hline Severe symptoms & 17 & $1.9 \%$ & 24 & $2.7 \%$ \\
\hline Total & 887 & $100 \%$ & 887 & $100 \%$ \\
\hline
\end{tabular}

score correlated with Polish ethnicity, living in a city rather than a village and in a district centre, a younger age and better education (Nagelkerke $=0.276)$ (Table 6). In the final variant, after the inclusion of both HAD subscales into the regression analysis, better satisfaction with $\mathrm{PHC}$ services was observed in respondents who were less depressed, of Polish ethnicity and who were living in a city rather than a village $($ Nagelkerke $=0.361)($ Table 7$)$.

\section{Discussion}

Our study shows that depressed and anxious patients had a negative opinion about healthcare services, and that was visible in all PSQ-18 subscale estimates.

The PSQ-18 and HAD subscales had the strongest coefficient correlation in the subscales General Satisfaction, Financial Aspects, Accessibility and Convenience, and Time Spent with Doctor. Similar results were obtained by Bair et al. [16]. They investigated the link between the diagnosed depression and patients' satisfaction with PHC services. The authors believe that depressed and anxious patients do not receive suitable psychological aid due to a relatively short consultation time. Moreover, they think that depressed patients receive PHC services more often, thus, they are more sensitive to the long waiting time. In order to examine the satisfaction of psychiatric outpatients with the health care services, Holikatti et al. also employed PSQ-18 questionnaire [17]. Their findings show that outpatients with Major Depressive Disorder and Anxiety Disorder were the most disappointed with the Financial Aspects and Communications.

We observed a strong connection between the symptoms of depression and anxiety. This relation is perceived by many scholars $[6,18-20]$. In our research, the symptoms of depression had a stronger influence on the outpatients' satisfaction than the symptoms of anxiety. Contrarily, Holikatti et al. found that the anxiety has a stronger influence on the satisfaction than depression and leads to worse satisfaction estimates [17].

We noticed that the nationality of patients affects the satisfaction of the services; however, this influence is still ambiguous. The majority of the subscales were evaluated the best by the Lithuanians. The satisfaction with the technical quality only received the higher evaluation from the Polish; nonetheless, this finding lacks the statistical reliability. The satisfaction of the Russians was very poor in all subscales. Typically, the ethnic minorities assessed the health care services worse than the national population. This could be caused by the lower reliance on the medical personnel [21], the self-isolation of the ethnic groups, and the longstanding political tendency to view themselves as different from the local majority [22]. 
Table 3 Spearman's correlation coefficients between Hospital Anxiety and Depression and Patient Satisfaction Questionnaire (Short Form) scores

\begin{tabular}{|c|c|c|c|c|}
\hline & & & HAD-Anxiety score & HAD-Depression score \\
\hline \multirow[t]{17}{*}{ Spearman's rho } & \multirow[t]{2}{*}{ General Satisfaction } & Correlation Coefficient & -.421 & -.470 \\
\hline & & Sig. (2-tailed) & .000 & .000 \\
\hline & \multirow[t]{2}{*}{ Technical Quality } & Correlation Coefficient & -.368 & -.430 \\
\hline & & Sig. (2-tailed) & .000 & .000 \\
\hline & \multirow[t]{2}{*}{ Interpersonal Manner } & Correlation Coefficient & -.356 & -.405 \\
\hline & & Sig. (2-tailed) & .000 & .000 \\
\hline & \multirow[t]{2}{*}{ Communication } & Correlation Coefficient & -.390 & -.453 \\
\hline & & Sig. (2-tailed) & .000 & .000 \\
\hline & \multirow[t]{2}{*}{ Financial Aspects } & Correlation Coefficient & -.432 & -.490 \\
\hline & & Sig. (2-tailed) & .000 & .000 \\
\hline & \multirow[t]{2}{*}{ Time Spent with Doctor } & Correlation Coefficient & -.390 & -.467 \\
\hline & & Sig. (2-tailed) & .000 & .000 \\
\hline & \multirow[t]{2}{*}{ Accessibility and Convenience } & Correlation Coefficient & -.446 & -.521 \\
\hline & & Sig. (2-tailed) & .000 & .000 \\
\hline & \multirow[t]{3}{*}{ Total PSQ-18 score } & Correlation Coefficient & -.462 & -.536 \\
\hline & & Sig. (2-tailed) & .000 & .000 \\
\hline & & $\mathrm{N}$ & 887 & 887 \\
\hline
\end{tabular}

Table 4 Ordinal regression analysis of Patient Satisfaction Questionnaire (Short Form) evaluation and respondents' sociodemographic factors as well as type of clinic (Nagelkerke $=0.100$ )

\begin{tabular}{|c|c|c|c|c|c|c|}
\hline \multirow{2}{*}{$\begin{array}{l}\text { Respondents' } \\
\text { characteristics }\end{array}$} & \multirow[t]{2}{*}{ Estimate } & \multirow[t]{2}{*}{ Std.Error } & \multirow[t]{2}{*}{ Wald } & \multirow[t]{2}{*}{ Sig. } & \multicolumn{2}{|c|}{ 95\% Confidence interval } \\
\hline & & & & & Lower Bound & Upper Bound \\
\hline Age & -.024 & .005 & 27.334 & .000 & -.033 & -.015 \\
\hline \multicolumn{7}{|l|}{ Gender: } \\
\hline Male & $0^{\mathrm{a}}$ & - & - & - & - & - \\
\hline Female & -.090 & .137 & .436 & .509 & -.358 & .177 \\
\hline \multicolumn{7}{|l|}{ Education level: } \\
\hline Secondary or lower & $0^{\mathrm{a}}$ & - & - & - & - & - \\
\hline Specialized secondary & -.531 & .200 & 7.034 & .008 & -.923 & -.138 \\
\hline Higher & .114 & .163 & .488 & .485 & -.206 & .434 \\
\hline \multicolumn{7}{|l|}{ Ethnicity: } \\
\hline Lithuanian & $0^{\mathrm{a}}$ & - & - & - & - & - \\
\hline Russian & .071 & .186 & .146 & .703 & -.294 & .436 \\
\hline Polish & -.460 & .190 & 5.881 & .015 & -.832 & -.088 \\
\hline \multicolumn{7}{|l|}{ Living area: } \\
\hline City & $0^{\mathrm{a}}$ & - & - & - & - & - \\
\hline District centre & .769 & .239 & 10.306 & .001 & .299 & 1.238 \\
\hline Village & 1.326 & .242 & 30.104 & .000 & .853 & 1.800 \\
\hline \multicolumn{7}{|l|}{ Type of the clinic: } \\
\hline State owner & $0^{a}$ & - & - & - & - & - \\
\hline Private owner & -.211 & .158 & 1.785 & .182 & -.520 & .098 \\
\hline
\end{tabular}


Table 5 Ordinal regression analysis of Patient Satisfaction Questionnaire (Short Form) evaluation and respondents' characteristics (with HAD-Depression subscale) (Nagelkerke $=0.385$ )

\begin{tabular}{|c|c|c|c|c|c|c|}
\hline \multirow{2}{*}{$\begin{array}{l}\text { Respondents' } \\
\text { characteristics }\end{array}$} & \multirow[t]{2}{*}{ Estimate } & \multirow[t]{2}{*}{ Std.Error } & \multirow[t]{2}{*}{ Wald } & \multirow[t]{2}{*}{ Sig. } & \multicolumn{2}{|c|}{ 95\% Confidence interval } \\
\hline & & & & & Lower Bound & Upper Bound \\
\hline HAD-Depression & -.329 & .024 & 185.725 & .000 & -.376 & -.281 \\
\hline Age & .005 & .006 & .698 & .404 & -.007 & .017 \\
\hline \multicolumn{7}{|l|}{ Chronic diseases: } \\
\hline No & $0^{\mathrm{a}}$ & - & - & - & - & - \\
\hline Yes & -.082 & .191 & .185 & .667 & -.455 & .291 \\
\hline \multicolumn{7}{|l|}{ Gender: } \\
\hline Male & $0^{a}$ & - & - & - & - & - \\
\hline Female & -.010 & .147 & .004 & .948 & -.298 & .278 \\
\hline \multicolumn{7}{|l|}{ Education level: } \\
\hline Secondary or lower & $0^{\mathrm{a}}$ & - & - & - & - & - \\
\hline Specialized secondary & -.328 & .218 & 2.269 & .132 & -.754 & .099 \\
\hline Higher & .164 & .180 & .832 & .362 & -.188 & .516 \\
\hline \multicolumn{7}{|l|}{ Ethnicity: } \\
\hline Lithuanian & $0^{\mathrm{a}}$ & - & - & - & - & - \\
\hline Russian & -.123 & .204 & .364 & .547 & -.523 & .277 \\
\hline Polish & -.686 & .208 & 10.877 & .001 & -1.094 & -.278 \\
\hline \multicolumn{7}{|l|}{ Living area: } \\
\hline City & $0^{\mathrm{a}}$ & - & - & - & - & - \\
\hline District centre & .309 & .265 & 1.360 & .243 & -.210 & .829 \\
\hline Village & 1.171 & .259 & 20.431 & .000 & .663 & 1.678 \\
\hline
\end{tabular}

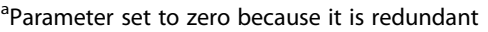

We found that the residency in the city causes a better satisfaction with services in all PSQ-18 subscales. The same results were also noticed in the pilot study [23]. As the inhabitants of villages are less educated and may have difficulties reaching the physician, the residency in the rural areas could be a reason for the poorer satisfaction with PHC services.

Generally, during the evaluation of PSQ-18 estimates, we noticed the remarkably low satisfaction estimates of Accessibility and Convenience, and Time Spent with Doctor. Such finding is confirmed by other studies, which found a correlation between the poor accessibility of PHC services, shorter consultation time and poorer satisfaction with the received PHC services [24, 25]. Michael et al. state that the satisfaction with PHC services improves if the waiting time before a consultation is shortened [26]. The authors suggest certain work methodologies, which would permit the reduction of the waiting time before a consultation. Anderson et al. found that the shorter consultation time was the strongest prognostic index causing poorer satisfaction [27]. These authors suggest that if the consultation time was extended by at least $5 \mathrm{~min}$, the patients would be more satisfied not only with the consultation, but also with the waiting time before a consultation. The availability of services in our research was slightly higher only in the private PHC clinics. Andersen et al. notice that the private clinics optimize non-clinical factors such as waiting time much more than the public ones [28]. Private clinics do not achieve noticeably better clinical results, thus the total patient satisfaction with private clinics is not always higher [29].

Recommendations: In order to improve the patient satisfaction with PHC services, the authors suggest the screening for the anxiety and depression symptoms among their patients; if found, those symptoms should be reduced. When the anxiety and depression symptoms are reduced, the satisfaction with the health care services can be expected to increase.

The increased satisfaction with the provided PHC services is important as the patients satisfied with the consultations are more likely to adhere to their treatment plan, take a better care of their health and lead a healthy lifestyle. This determines better outcomes of their treatment [24]. In order to reach such goals, it is important to give information to patients with the symptoms of anxiety and depression about medical and social assistance, and psychological support opportunities. It is also 
Table 6 Ordinal regression analysis of Patient Satisfaction Questionnaire (Short Form) evaluation and respondents' characteristics (with HAD-Anxiety subscale) (Nagelkerke $=0.276$ )

\begin{tabular}{|c|c|c|c|c|c|c|}
\hline \multirow{2}{*}{$\begin{array}{l}\text { Respondents' } \\
\text { characteristics }\end{array}$} & \multirow[t]{2}{*}{ Estimate } & \multirow[t]{2}{*}{ Std.Error } & \multirow[t]{2}{*}{ Wald } & \multirow[t]{2}{*}{ Sig. } & \multicolumn{2}{|c|}{ 95\% Confidence interval } \\
\hline & & & & & Lower Bound & Upper Bound \\
\hline HAD-Anxiety & -.233 & .023 & 106.876 & .000 & -.277 & -.189 \\
\hline Age & -.014 & .006 & 6.177 & .013 & -.025 & -.003 \\
\hline \multicolumn{7}{|l|}{ Chronic diseases: } \\
\hline No & $0^{\mathrm{a}}$ & - & - & - & - & - \\
\hline Yes & -.096 & .187 & .267 & .605 & -.462 & .269 \\
\hline \multicolumn{7}{|l|}{ Gender: } \\
\hline Male & $0^{a}$ & - & - & - & - & - \\
\hline Female & -.138 & .143 & .927 & .336 & -.418 & .142 \\
\hline \multicolumn{7}{|l|}{ Education level: } \\
\hline Secondary or lower & $0^{\mathrm{a}}$ & - & - & - & - & - \\
\hline Specialized secondary & -.604 & .210 & 8.308 & .004 & -1.015 & -.193 \\
\hline Higher & .082 & .174 & .224 & .636 & -.259 & .424 \\
\hline \multicolumn{7}{|l|}{ Ethnicity: } \\
\hline Lithuanian & $0^{a}$ & - & - & - & - & - \\
\hline Russian & -.157 & .194 & .653 & .419 & -.224 & .537 \\
\hline Polish & -.532 & .201 & 6.996 & .008 & -.927 & -.138 \\
\hline \multicolumn{7}{|l|}{ Living area: } \\
\hline City & $0^{\mathrm{a}}$ & - & - & - & - & - \\
\hline District centre & .599 & .254 & 5.576 & .018 & .102 & 1.096 \\
\hline Village & 1.283 & .251 & 26.184 & .000 & .792 & 1.774 \\
\hline
\end{tabular}

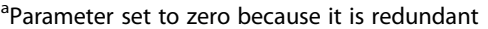

Table 7 Ordinal regression analysis of Patient Satisfaction Questionnaire (Short Form) evaluation and respondents' characteristics (with both HAD-Depression and HAD-Anxiety subscales) (Nagelkerke $=0.361$ )

\begin{tabular}{|c|c|c|c|c|c|c|}
\hline \multirow{2}{*}{$\begin{array}{l}\text { Respondents' } \\
\text { characteristics }\end{array}$} & \multirow[t]{2}{*}{ Estimate } & \multirow[t]{2}{*}{ Std.Error } & \multirow[t]{2}{*}{ Wald } & \multirow[t]{2}{*}{ Sig. } & \multicolumn{2}{|c|}{ 95\% Confidence interval } \\
\hline & & & & & Lower Bound & Upper Bound \\
\hline HAD-Anxiety & -.042 & .029 & 2.208 & .137 & -.098 & .014 \\
\hline HAD-Depression & -.300 & .029 & 103.723 & .000 & -.358 & -.243 \\
\hline Age & .006 & .006 & 1.194 & .274 & -.005 & .018 \\
\hline \multicolumn{7}{|l|}{ Chronic diseases: } \\
\hline No & $0^{a}$ & - & - & - & - & - \\
\hline Yes & -.244 & .181 & 1.808 & .179 & -.599 & .111 \\
\hline \multicolumn{7}{|l|}{ Gender: } \\
\hline Male & $0^{\mathrm{a}}$ & - & - & - & - & - \\
\hline Female & -.004 & .144 & .001 & .977 & -.286 & .278 \\
\hline \multicolumn{7}{|l|}{ Ethnicity: } \\
\hline Lithuanian & $0^{\mathrm{a}}$ & - & - & - & - & - \\
\hline Polish & -.505 & .186 & 7.372 & .000 & -.869 & -.140 \\
\hline \multicolumn{7}{|l|}{ Living area: } \\
\hline City & $0^{\mathrm{a}}$ & - & - & - & - & - \\
\hline District centre & .272 & .258 & 1.115 & .291 & -.233 & .777 \\
\hline Village & .768 & .235 & 10.622 & .001 & .305 & 1.229 \\
\hline
\end{tabular}

Parameter set to zero because it is redundant 
important to regularly develop the emotional support and cooperation skills for students of medicine and employees of family centers. These skills should be actively used during the problem solving of the depressed and anxious patients.

The advantages of this study are a reasonably large survey sample, and the usage of PSQ-18 and HAD scales together in the primary health care level research. The fact that research only included residents of one region of a country presents the limitation of our study; the situation further away from the capital city may be different. Also, patients who did not understand the national language could not complete the questionnaire; the opinion of ethnic minority patients, who are only native speakers, could be different also.

\section{Conclusions}

The worse satisfaction with PHC services is associated with the higher degree of outpatients' symptoms of depression and anxiety, and their residency in the district centre or countryside; the found association between the nationality of patients and their satisfaction with PHC services was ambiguous. The symptoms of depression and anxiety of outpatients strongly correlate between each other. The satisfaction with the PHC services was more influenced by social and cultural (place of residence or nationality) than by demographic (age and gender) factors. The authors recommend the active patient screening for symptoms of depression and anxiety, and their reduction, in order to improve the satisfaction with PHC services.

\section{Abbreviations}

HAD: Hospital Anxiety and Depression Scale; HAD-A: Hospital Anxiety and Depression Scale's Anxiety Subscale; HAD-D: Hospital Anxiety and Depression Scale's Depression Subscale; PHC: Primary Healthcare; PSQ-18: Patient Satisfaction Questionnaire, Short Version

\section{Funding}

No funding was received except for the authors' personal resources.

\section{Availability of data and materials}

The datasets used and analysed during the current study are available from the corresponding author on reasonable request.

\section{Authors' contributions}

RK worked on the data collection and the calculation of results and was the major contributor in writing the manuscript. AD participated in setting the main aim of the research, in computing the data and writing the manuscript. VK, V̌̌, RA proposed the main trial idea and worked on the choice of research methods. LA was the major contributor in the data collection and in entering it into a statistical program. All of the authors read and approved the final manuscript.

\section{Ethics approval and consent to participate}

The study proposal was approved by the Regional Biomedical Research Ethics Committee in Vilnius, Lithuania; Number 158200-15-795-313. The Regional Biomedical Research Ethics Committee freed investigators from the informed consent form (this is written on permission to conduct biomedical research), because in this study an anonymous survey was used and no patient personal data was requested. After first reading the questionnaire's information page, patients who agreed to participate simply filled out the questionnaire, and patients who didn't agree did not fill it out.

\section{Competing interests}

The authors declare that they have no competing interests.

\section{Publisher's Note}

Springer Nature remains neutral with regard to jurisdictional claims in published maps and institutional affiliations.

\section{Author details}

${ }^{1}$ Institute of Clinical Medicine of the Faculty of medicine of Vilnius University, Clinic of Internal Diseases, Family Medicine and Oncology, Santariskiu g. 2, Vilnius, Lithuania. ${ }^{2}$ Nordland Hospital, Parkveien, 95 Bodø, Norway. ${ }^{3}$ Institute of Clinical Medicine of the Faculty of medicine of Vilnius University, Clinic of Psychiatry, Vasaros g.5, Vilnius, Lithuania. ${ }^{4}$ Faculty of medicine of Vilnius University, Čiurlionio g, 21 Vilnius, Lithuania.

Received: 10 January 2018 Accepted: 25 May 2018

Published online: 19 June 2018

\section{References}

1. World Health Organization. Mental Disorders in Primary Care. A WHO Educational Package. WHO/MSA/MNHIEAC/98.1; 1998. http://apps.who.int/ iris/handle/10665/67186.

2. Sadeniemi M, Pirkola S, Pankakoski M, Joffe G, Kontio R, Malin M, et al. Does primary care mental health resourcing affect the use and cost of secondary psychiatric services? Int J Environ Res Public Health. 2014;11(9):8743-54. https://doi.org/10.3390/ijerph110908743.

3. Sundquist J, Ohlsson H, Sundquist K, Kendler KS. Common adult psychiatric disorders in Swedish primary care where most mental patients are treated. BMC Psychiatry. 2017;17(1):235. https://doi.org/10.1186/s12888-017-1381-4.

4. Olatunji BO, Cisler JM, Tolin DF. Quality of life in the anxiety disorders: a meta-analytic review. Clin Psychol Rev. 2007;27(5):572-81.

5. Joffe H, Chang Y, Dhaliwal S, Hess R, Thurston R, Gold E. Lifetime history of depression and anxiety disorders predicts low quality-of-life in midlife women in the absence of current illness episodes. Arch Gen Psychiatry. 2012;69(5):484-92. https://doi.org/10.1001/archgenpsychiatry.2011.1578.

6. IsHak WW, Mirocha J, Christensen S, Wu F, Kwock R, Behjat J, et al. Patientreported outcomes of quality of life, functioning, and depressive symptom severity in major depressive disorder comorbid with panic disorder before and after SSRI treatment in the star*d trial. Depress Anxiety. 2014;31(8): 707-16. https://doi.org/10.1002/da.22152.

7. Spernak SM, Moore PJ, Hamm LF. Depression, constructive thinking and patient satisfaction in cardiac treatment adherence. Psychol Health Med. 2007:12(2):172-89.

8. Bui QU, Ostir GV, Kuo YF, Freeman J, Goodwin JS. Relationship of depression to patient satisfaction: findings from the barriers to breast cancer study. Breast Cancer Res Treat. 2005;89(1):23-8.

9. Bassett J, Adelman A, Gabbay R, Aňel-Tiangco RM. Relationship between Depression and Treatment Satisfaction among Patients with Type 2 Diabetes. J Diabetes Metab. 2012;3(7):1000210. https://doi.org/10.4172/2155-6156.1000210.

10. Jung HY, Jang HM, Kim YW, Cho S, Kim HY, Kim SH, et al. Depressive Symptoms, Patient Satisfaction, and Quality of Life Over Time in Automated and Continuous Ambulatory Peritoneal Dialysis Patients. A Prospective Multicenter Propensity-Matched Study. Med (Baltimore). 2016;95(21):e3795. https://doi.org/10.1097/MD.0000000000003795.

11. Pijnenborg AAMM. Anxiety and overall patient satisfaction in cataract patients: reducing the impact of anxiety by special adjustments of care delivery: Tilburg University; 2009. http://arno.uvt.nl/show.cgi?fid=97339. Accessed 15 Dec 2017

12. Herrera-Espiñeira C, Rodríguez del Aguila Mdel M, Rodríguez del Castillo M, Valdivia AF, Sánchez IR. Relationship between anxiety level of patients and their satisfaction with different aspects of healthcare author links open overlay panel. Health Policy. 2009;89(1):37-45. https://doi.org/10.1016/j.healthpol.2008.04.012.

13. Boinon D, Dauchy S, Charles C, Fasse L, Cano A, Balleyguier C, et al. Patient satisfaction with a rapid diagnosis of suspicious breast lesions: association with distress and anxiety. Breast J. 2017; https://doi.org/10.1111/tbj.12856.

14. World Health Organization. Depression and Other Common Mental Disorders. Global Health Estimates: WHO/MSD/MER/2017.2; 2017. http:// www.who.int/mental_health/management/depression/prevalence_global_ health_estimates/en/. 
15. Buszewicz MJ, Chew-Graham C. Improving the detection and management of anxiety dosorders in primary care. Br J Gen Pract. 2011;61(589):489-90. https://doi.org/10.3399/bjgp11X588259.

16. Bair MJ, Kroenke K, Sutherland JM, McCoy KD, Harris H, McHorney CA. Effects of depression and pain severity on satisfaction in medical outpatients: analysis of the medical outcomes study. J Rehabil Res Dev. 2007:44(2):143-52.

17. Holikatti PC, Kar N, Mishra A, Shukla R, Swain SP, Kar S. A study on patient satisfaction with psychiatric services. Indian J Psychiatry. 2012;54(4):327-32.

18. Campbell-Sills L, Sherbourne CD, Roy-Byrne P, Craske MG, Sullivan G, Bystritsky $A$, et al. Effects of co-occurring depression on treatment for anxiety disorders: analysis of outcomes from a large primary care effectiveness trial. J Clin Psychiatry. 2012;73(12):1509-16.

19. Stavrakaki C, Vargo B. The relationship of anxiety and depression: a review of the literature. Br J Psychiatry. 1986:149:7-16.

20. Cummings CM, Caporino NE, Kendall PC. Comorbidity of anxiety and depression in children and adolescents: 20 years after. Psychol Bull. 2014; 140(3):816-45

21. Pinder RJ, Ferguson J, Møller H. Minority ethnicity patient satisfaction and experience: results of the National Cancer Patient Experience Survey in England. BMJ Open. 2016;6(6):e011938.

22. Kersnik J, Ropret T. An evaluation of patient satisfaction amongst family practice patients with diverse ethnic backgrounds. Swiss Med Wkly. 2002; 132(9-10):121-4.

23. Aranauskas R, Deksnytè A, Makulytè G, Aranauskienè A. The influence of social and demographic factors on patient satisfaction with primary care. Health Sci. 2010;2(20):2994-9.

24. Nunu WN, Munyewende PO. Patient satisfaction with nurse-delivery primary health care services in free state and Gauteng provinces, South Africa: a comparative study. Afr J Prim Health Care Fam Med. 2017;9(1):1262.

25. Lionis C, Papadakis S, Tatsi C, Bertsias A, Duijker G, Mekouris PB, et al. Informing primary care reform in Greece:patient expectations and experiences (the QUALICOPC study). BMC Health Serv Res. 2017;17:255.

26. Michael M, Schaffer SD, Egan PL, Little BB, Pritchard PS. Improving wait times and patient satisfaction in primary care. J Healthc Qual. 2013;35(2):50-9.

27. Anderson RT, Camacho FT, Balkrishnan R. Willing to wait? : The influence of patient wait time on satisfaction with primary care. BMC Health Serv Res. 2007;7:31.

28. Andersen LB, Jakobsen ML. Does ownership matter for the provision of professionalized services? Hip operations at publicly and privately owned clinics in Denmark. Public Adm. 2011;89(3):956-74.

29. Maun A, Wessman C, Sundvall PD, Thorn J, Björkelund C. Is the quality of primary healthcare services influenced by the healthcare centre's type of ownership?-an observational study of patient perceived quality, prescription rates and follow-up routines in privately and publicly owned primary care centres. BMC Health Serv Res. 2015:15:417.

\section{Ready to submit your research? Choose BMC and benefit from:}

- fast, convenient online submission

- thorough peer review by experienced researchers in your field

- rapid publication on acceptance

- support for research data, including large and complex data types

- gold Open Access which fosters wider collaboration and increased citations - maximum visibility for your research: over $100 \mathrm{M}$ website views per year

At BMC, research is always in progress.

Learn more biomedcentral.com/submissions 